\title{
PENGARUH KEBUTUHAN DAN KEMAMPUAN DIRI SERTA GENDER TERHADAP INTENSI BERWIRAUSAHA
}

\author{
Niqo Ahmad \\ niqoahmad@gmail.com \\ Fakultas Psikologi UIN Syarif Hidayatullah Jakarta
}

\begin{abstract}
This research aimed to measure the impact of need for achievement, need for autonomy, entrepreneurial self-efficacy, internal locus of control, external locus of control, risk taking propensity, and gender upon the intention of a 20 vocational high school Jakarta entrepreneurship. The sample of this research was the 233 students of 20 vocational high school which was taken with probability sampling through proportionate stratified random sampling technique. The data analysis used in this research is a multiple regression analysis on significance level of 0,05. The result showed that there are significant impacts of need for achievement, need for autonomy, entrepreneurial self-efficacy, internal locus of control, external locus of control, risk taking propensity, and gender upon the intention of a 20 vocational high school Jakarta entrepreneurship. The variance proportion of entrepreneurial intervention which described in the independent variable was $22.6 \%$, meanwhile the rest of $77.4 \%$ was influenced by the other variable excluded in this research. The result of the minor hypothesis test showed that need for autonomy, entrepreneurial self-efficacy, and internal locus of control had significant influence towards the entrepreneurship intention. However, the need for achievement, external locus of control, risk taking propensity, and gender variable did not have any significant influence towards the entrepreneurship intention .
\end{abstract}

Keywords: entrepreneurship intention, need for achievement, need for autonomy, entrepreneurial self-efficacy, internal locus of control, external locus of control, risk taking propensity, gender.

\begin{abstract}
Abstrak
Penelitian ini dilakukan untuk mengukur pengaruh need for achievement, need for autonomy, entrepreneurial self-efficacy, internal locus of control, external locus of control, risk taking propensity, dan gender terhadap intensi berwirausaha siswa SMK Negeri 20 Jakarta. Sampel dalam penelitian ini adalah siswa SMKN 20 Jakarta sebanyak 233 siswa. Jenis pengambilan sampel dalam penelitian ini adalah probability sampling dengan teknik proportionate stratified random sampling. Analisis data yang digunakan adalah analisis regresi berganda pada taraf signifikansi 0,05 . Hasil penelitian menunjukkan bahwa ada pengaruh yang signifikan need for achivement, need for autonomy, entrepreneurial self-efficacy, internal locus of control, external locus of control, risk taking propensity, dan gender terhadap intensi berwirausaha siswa SMKN 20 Jakarta. Proporsi varians dari intensi berwirausaha yang dijelaskan variabel independen yang
\end{abstract}


digunakan adalah sebesar $22.6 \%$, sedangkan $77.4 \%$ sisanya dipengaruhi oleh variabel lain di luar penelitian ini. Hasil uji hipotesis minor menunjukkan bahwa need for autonomy, entrepreneurial self-efficacy, dan internal locus of control memiliki pengaruh yang signifikan terhadap intensi berwirausaha. Sementara itu, variabel need for achievement, external locus of control, risk taking propensity, dan gender tidak memiliki pengaruh signifikan terhadap intensi berwirausaha.

Kata kunci: intensi berwirausaha, need for achievement, need for autonomy, entrepreneurial self-efficacy, internal locus of control, external locus of control, risk taking propensity, gender

\section{PENDAHULUAN}

Kewirausahaan memiliki peran penting dalam perekonomian suatu negara, berkontribusi menyediakan penciptaan bisnis baru atau peluang bisnis di perusahaan yang sudah ada. Oleh karena itu, kewirausahaan membawa serangkaian keuntungan untuk negara ataupun wilayah, dengan penciptaan bisnis baru yang menghasilkan lebih banyak investasi dalam ekonomi lokal, menciptakan lapangan kerja baru, dan meningkatkan daya saing dengan mengembangkan alat kerja yang inovatif (Campo, 2011), Konsep kewirausahaan telah menarik perhatian pemerintah, akademisi, industrialis, ekonom, dan para pelajar. Hal ini dibuktikan dalam sejumlah seminar, konferensi dan lokakarya yang diselenggarakan di tingkat internasional, regional dan nasional dengan penekanan pada kebutuhan untuk peka individu, masyarakat, dan negara untuk memulai berwirausaha (Ogundipe, et al., 2012).

Penelitian mengenai faktor-faktor psikologis yang berhubungan dengan intensi berwirausaha telah banyak dilakukan oleh para peneliti. Salah satunya Guifang, et al., (2012) dalam penelitiannya yang menunjukkan bahwa pendidikan kewirausahaan dapat meningkatkan intensi berwirausaha secara tidak langsung dengan memperbarui pengetahuan siswa, mengolah kemampuan kewirausahaan dan memperkuat tekad (Guifang, et al., 2012). Salah satu pendidikan berbasis kewirausahaan di Indonesia adalah Sekolah Menengah Kejuruan/SMK (Mahshunah. 2010).

SMK merupakan sarana pendidikan berbasis kewirausahaan, sehingga diharapkan lulusan SMK dapat menjadi mandiri, membuka lapangan pekerjaan atau berwirausaha, serta dapat menjawab tantangan tenaga kerja khususnya di Indonesia. Dalam kenyataannya, berdasarkan Badan Pusat Statistik (BPS) pada Berita Resmi Statistik No. 75/11/Th. XV, 5 November 2012 menunjukkan bahwa pada bulan Agustus tahun 2012 Tingkat Pengangguran Terbuka (TPT) menurut pendidikan tertinggi yang 
ditamatkan paling tinggi adalah tingkat SMK yaitu 9,87\%. (www.bps.go.id/getfile.php?news=970 diunduh pada tanggal 27 Desember 2012 pukul 11.40 WIB)

Berdasarkan pertimbangan tersebut di atas maka intensi berwirausaha pada siswa SMK penting untuk diteliti. Berdasarkan penelitian terdahulu diketahui faktor-faktor yang memengaruhi intensi berwirausaha diantaranya need for achievement (Dehkordi, et al., 2012; Indira dan Soenhadji, 2010; Nishantha, Busige, 2009; Opoku-Antwi, et al., 2012; Zain, et al., 2010), need for autonomy (Fatoki, 2010), entrepreneurial self-efficacy (Khodabakhshi \& Talebi, 2012; Izquierdo \& Buelens, 2008; Hashemi, Hosseini, dan Rezvanfar, 2012; Mobaraki dan Zare, 2012), locus of control (Nishantha, Busige, 2009; Opoku-Antwi, et al., 2012; Zain, Zahariah, et al., 2010), risk taking propensity (Nishantha, Busige, 2009; Hmieleski dan Corbett, 2006), dan gender (Nishantha, Busige, 2009).

Hasil penelitian yang telah dilakukan oleh Dehkordi, et al., (2012) menemukan bahwa need for achievement merupakan faktor paling penting yang memengaruhi intensi berwirausaha. Apabila tingkat need for achievement seseorang rendah, maka kemungkinan intensi berwirausahanya akan rendah. Sebaliknya apabila tingkat need for achievement seseorang tinggi, maka dapat dikatakan memiliki kecenderungan intensi berwirausaha akan tinggi pula. Need for autonomy yang juga digunakan juga sangat berpengaruh terhadap intensi berwirausaha. Penelitian yang dilakukan Fatoki (2010) menyebutkan bahwa need for autonomy juga memengaruhi intensi berwirausaha. Tinggi rendahnya tingkat need for autonomy akan menentukan tinggi rendahnya intensi berwirausaha.

Variabel lain yaitu entrepreneurial self-efficacy, merupakan keyakinan seseorang dalam kemampuan diri sendiri untuk mampu melakukan berbagai keterampilan yang diperlukan untuk melakukan peluang usaha baru (De Noble, et al., 1999). Khodabakhshi \& Talebi, 2012; Izquierdo \& Buelens, 2008; Hashemi, Hosseini, dan Rezvanfar, 2012; Mobaraki dan Zare, 2012 menemukan bahwa entrepreneurial self-efficacy memengaruhi intensi berwirausaha. Jadi, ketika siswa yang memiliki entrepreneurial selfefficacy yang tinggi maka intensi dalam berwirausaha kemungkinan akan tinggi, karena akan merasa mampu menjalankannya. Sedangkan apabila entrepreneurial self-efficacy yang dimiliki rendah, secara otomatis menandakan bahwa ada ketidakyakinan apakah mampu berwirausaha atau tidak dan membuat intensi berwirausahanya menjadi rendah.

Selanjutnya dijelaskan mengenai locus of control, yaitu keyakinan seseorang mengenai sumber penentu perilaku. Konsep locus of control ada dua, yaitu internal dan ekternal (Levenson, 1981). Siswa yang memiliki internal locus of control tinggi mempunyai keyakinan bahwa apa yang terjadi pada dirinya, kegagalan atau keberhasilan karena pengaruh dirinya sendiri. Sedangkan siswa yang memiliki external locus of control tinggi mempunyai anggapan bahwa faktor yang ada di luar dirinya akan memengaruhi tingkah 
lakunya seperti kesempatan, nasib, dan keberuntungan. Dalam hal ini apabila siswa memiliki internal locus of control tinggi, maka dapat diketahui bahwa intensi berwirausaha pada siswa tersebut bersumber dari dalam dirinya. Sedangkan apabila external locus of control tinggi, maka dapat diketahui bahwa intensi berwirausaha dipengaruhi oleh faktor luar.

Faktor lain yang digunakan dalam penelitian ini adalah risk taking propensity. Istilah kewirausahaan selalu dikaitkan dengan pengambilan risiko (risk taking), didukung dari definisi awal kewirausahaan yaitu proses menanggung risiko ketika pengusaha melibatkan dalam membeli barang dengan harga tertentu dan menjualnya dengan harga yang tidak pasti (DiMasi, 2004 dalam Hassan \& Wafa, 2012). Hal ini menjelaskan mengapa beberapa definisi kewirausahaan selalu berhubungan dengan keberanian mengambil risiko (risk taking). Menurut Haftendorn (2003) dalam Hassan \& Wafa (2012), kualitas kewirausahaan atau perilaku berusaha meliputi kemauan untuk mengambil risiko. Di-Masi (2004) juga mendukung bahwa karakteristik utama dari wirausaha salah satunya pengambilan risiko (risk taking). Hal ini menyiratkan bahwa bagi pengusaha untuk berhasil berarti harus berani mengambil risiko (risk taking).

\section{KAJIAN TEORI}

\section{Teori dan Hipotesis}

1. Intensi berwirausaha

Fishbein \& Ajzen (1975) menyatakan, "We have define intention as a person's location on a subjective probability dimension involving a relation between himself and some action. A behavioral intention, therefore, refers to a person's subjective probability that they will perform some behavior." Dari definisi di atas, intensi diartikan sebagai posisi seseorang pada dimensi probabilitas subyektif yang mencakup hubungan antara dirinya dan suatu perilaku. Intensi berperilaku, oleh karena itu merujuk pada probabilitas subyektif seseorang yang akan menampilkan suatu perilaku.

Dalam Theory of Planned Behavior Ajzen (1991) menyatakan, "Intentions are assumed to capture the motivational factors that influence a behavior; they are indications of how hard people are willing to try, of how much of an effort they are planning to exert, in order to perform the behavior." Dari pernyataan di atas, intensi diasumsikan untuk menangkap faktor-faktor motivasi yang memiliki pengaruh terhadap perilaku. Hal tersebut merupakan indikasi seberapa kuat keinginan seseorang untuk mencoba dan seberapa banyak upaya yang direncanakan untuk memunculkan perilaku tersebut.

Istilah wirausaha sudah dikenal orang dalam sejarah ilmu ekonomi sebagai ilmu pengetahuan sejak tahun 1755. Seorang Perancis yang bernama Richard Cantillon, ahli ekonomi Perancis 
keturunan Irlandia dianggap sebagai orang pertama yang menggunakan istilah entrepreneur atau wirausaha (Winardi, 2004). Wirausaha menurut Baker \& Nelson (2005) dalam Brown (2010) adalah usaha mengumpulkan sumber daya, tenaga kerja, bahan, dan aset lainnya menjadi kombinasi yang membuat nilai mereka lebih besar daripada sebelumnya dan disertai perubahan dan inovasi. Fatoki (2010) menjelaskan bahwa kewirausahaan adalah kemampuan dan kemauan untuk melakukan konsepsi, organisasi, dan manajemen usaha produktif dengan semua risiko yang menyertainya, sedangkan keuntungan sebagai hadiahnya. Suryana (2009) mendefinisikan wirausaha sebagai kemampuan kreatif dan inovatif yang dijadikan dasar, kiat dan sumber daya untuk mencari peluang menuju sukses. Suryana (2009) menjelaskan bahwa kewirausahaan merupakan suatu kemampuan dalam menciptakan nilai tambah di pasar melalui proses pengelolaan sumber daya dengan cara-cara baru dan berbeda melalui:

1. Pengembangan teknologi baru.

2. Penemuan pengetahuan ilmiah baru.

3. Perbaikan produk barang dan jasa yang ada.

4. Penemuan cara-cara baru untuk menghasilkan barang lebih banyak dengan sumber daya yang lebih efisien.

Thompson (2009) menjelaskan intensi berwirausaha sebagai keyakinan diri yang diakui oleh individu bahwa berniat untuk mendirikan sebuah usaha bisnis baru dan secara sadar berencana untuk melakukannya di masa depan. Guifang, et al., (2012) menyebutkan intensi berwirausaha adalah suatu kondisi psikologis wirausahawan yang berfokus pada tujuan yang spesifik dengan semua pikiran, energi dan perilaku. Hal ini merupakan prasyarat bagi seseorang untuk memulai bisnis dan mencerminkan keandalan untuk membuat bisnis baru. Gubruz \& Aykol (2008) mendefinisikan intensi berwirausaha sebagai kesediaan seseorang dalam melakukan aktivitas kewirausahaan. Jadi, intensi berwirausaha dalam penelitian ini merupakan suatu kondisi psikologis yang berfokus pada tujuan yang spesifik serta diyakini oleh individu untuk berniat memulai sebuah usaha dan secara sadar berencana melakukannya di masa depan.

2. Need for achievement

Murray (1938) mendefinisikan need for achievement sebagai seseorang yang dapat memimpin dan mengatur orang lain, menyelesaikan tugas yang sulit, menyelesaikan tugas dengan cepat tanpa bantuan orang lain, mengatasi kendala dengan baik, dan mengungguli para pesaingnya (Larsen \& Buss, 2002). Ripinen (1994) dalam Prihatsanti (2010) mendefinisikan need for achievement sebagai kebutuhan yang mengacu pada pencapaian tugas atau tujuan yang kuat dan obsesi yang berorientasi pada pekerjaan atau tugas yang harus dilakukan. Kebutuhan akan prestasi juga dapat diartikan sebagai suatu kesatuan 
watak yang memotivasi seseorang untuk menghadapi tantangan untuk mencapai kesuksesan dan keunggulan (Lee, 1997 dalam Indarti \& Rostiani, 2008).

McClelland adalah tokoh paling dikenal dalam penelitian tentang need for achievement. McClelland membuat teori yang dikenal dengan The Big Three Motives yang salah satu dari motif tersebut adalah need for achievement (Larsen \& Buss, 2002). Lebih lanjut McClelland mendefinisikannya sebagai keinginan untuk berbuat lebih baik, untuk menjadi sukses, dan untuk merasa berkompeten (Larsen \& Buss, 2002). McClelland juga menegaskan seperti halnya semua motif, yaitu need for achievement akan memberikan energi untuk bertindak pada situasi tertentu (Larsen \& Buss, 2002).

Menurut Edwards (1959) dalam Umar (2010) need for achievement adalah keinginan untuk bekerja sebaik mungkin, ingin sukses, ingin berhasil dalam tugas-tugas yang menuntut keahlian serta usaha, ingin diakui sebagai orang yang berkemampuan di dalam bidang tertentu, mencapai sesuatu yang cukup berarti, menyelesaikan tugas-tugas yang sukar, memecahkan permasalahan-permasalahan yang sulit, dan biasa mengerjakan segala sesuatu lebih baik daripada orang lain. Need for achievement menurut Pinder (1984) dalam Ariani (2008) adalah pencapaian sesuatu yang sulit untuk menguasai, memanipulasi, atau mengorganisir sasaran fisik, manusia atau ideide, untuk mengerjakan secara cepat dan independen, untuk menyaingi atau melebihi orang lain, dan untuk meningkatkan hal-hal yang berkaitan dengan target. Pinder (1984) dalam Ariani (2008) juga mengatakan bahwa need for achievement merupakan suatu kesempatan untuk bersaing dengan standards of excellence yang berkaitan dengan positive outcome. Jadi, need for achievement dalam penelitian ini yaitu seseorang yang dapat memimpin dan mengatur orang lain, menyelesaikan tugas yang sulit, menyelesaikan tugas dengan cepat tanpa bantuan orang lain, mengatasi kendala dengan baik, dan mengungguli para pesaingnya.

3. Need for autonomy

Dalam Kamus Psikologi kata autonomy diartikan sebagai keadaan pengaturan diri, atau kebebasan individu manusia untuk memilih, menguasai, dan menentukan dirinya sendiri (Chaplin, 2001). Sedangkan Murray (1938) menjelaskan need for autonomy sebagai seseorang yang membebaskan diri dari aturan yang mengekang, melawan paksaan dan hambatan, menghindari kekuasaan orang lain, bertindak bebas sesuai dengan keinginan sendiri, dan tidak memiliki keterikatan (Larsen \& Buss, 2002). Berdasarkan penelitian yang dilakukan oleh Murray, terdapat daftar 'fundamental needs' yang masing-masing need dikelompokkan menjadi tiga kategori yaitu ambition needs, need to defend status, needs related to social power, social 
affection needs, dan needs related to information exchange. Sedangkan autonomy termasuk ke dalam needs related to social power (Larsen \& Buss, 2002).

Puffer (1987) dalam Ariani (2008) mendefinisikan need for autonomy sebagai keinginan untuk mandiri atau independen, dan lebih memilih untuk mengendalikan pekerjaannya sendiri. Menurut Edwards (1959) dalam Umar (2010) need for autonomy adalah ingin dapat berbuat sesuatu sesuai dengan kehendaknya, menyatakan pendapatnya dalam segala hal, bebas dari orang lain dalam menentukan sesuatu, merasa bebas untuk melakukan apa yang diinginkan, melakukan hal-hal yang menyimpang dari kebiasaan, menghindari situasi-situasi di mana orang diharapkan menyesuaikan dirinya, mengerjakan sesuatu tanpa peduli akan pendapat orang lain atas hal itu, kritik kepada orang yang menduduki posisi kekuasaan, mengelakkan tanggung jawab dan kewajiban-kewajiban. Jadi, need for autonomy dalam penelitian ini yaitu seseorang yang membebaskan diri dari aturan yang mengekang, melawan paksaan dan hambatan, menghindari kekuasaan orang lain, bertindak bebas sesuai dengan keinginan sendiri, dan tidak memiliki keterikatan.

4. Entrepreneurial self-efficacy

Bandura merupakan salah satu tokoh yang memperkenalkan istilah self-efficacy. Bandura sendiri banyak memberikan definisi tentang selfefficacy. Menurut Bandura self-efficacy adalah keyakinan bahwa seseorang dapat menguasai situasi dan dapat memberikan hasil positif (Santrock, 2009). Dalam Hmieleski \& Baron, 2008), Bandura menjelaskan bahwa self-efficacy adalah evaluasi seseorang terhadap kemampuan atau kompetensinya untuk melakukan sebuah tugas, mencapai tujuan, mengatasi hambatan.

Bandura (dalam Feist \& Feist, 2002), mendefinisikan self-efficacy sebagai keyakinan seseorang dalam kemampuannya melakukan suatu bentuk kontrol terhadap keberfungsian orang itu sendiri dan kejadian dalam lingkungannya. Sedangkan dalam Friedman dan Schustack (2009), Bandura (1997) menjelaskan self-efficacy adalah ekspektasi (harapan) tentang seberapa jauh seseorang mampu melakukan suatu perilaku dalam suatu situasi tertentu. Dalam Friedman dan Schustack (2009) juga dijelaskan bahwa keyakinan tentang self-efficacy merupakan hasil dari 4 jenis informasi, yaitu: (1) pengalaman individu dalam melakukan perilaku yang diharapkan atau perilaku yang serupa (kesuksesan dan kegagalan di masa lalu); (2) melihat orang lain melakukan perilaku tersebut atau perilaku yang kurang lebih sama (vicarious experience); (3) persuasi verbal (bujukan orang lain yang bertujuan untuk menyemangati atau menjatuhkan performa); dan (4) bagaimana perasaan individu tentang perilaku yang dimaksud (reaksi emosional). Sementara itu, Woolfolk (2009) mendefinisikan 
self-efficacy sebagai keyakinan tentang kompetensi atau efektivitas kita di bidang tertentu. Berdasarkan beberapa pendapat ahli di atas, dapat disimpulkan bahwa self-efficacy adalah keyakinan individu mengenai kemampuan dirinya untuk melakukan suatu tugas, mencapai suatu tujuan, dan mengatasi hambatan.

Memahami entrepreneurial self-efficacy (ESE) penting, karena dapat memengaruhi kesediaan individu untuk terlibat dalam kewirausahaan serta untuk yang sudah menjadi pengusaha (Mobaraki \& Zare, 2012). De Noble, et al., (1999) menjelaskan bahwa entrepreneurial self-efficacy adalah keyakinan seseorang dalam kemampuan sendiri untuk mampu melakukan berbagai keterampilan yang diperlukan untuk membuat peluang usaha baru. Menurut Campo (2011) entrepreneurial self-efficacy (ESE) adalah kemampuan seseorang yang dapat memodifikasi keyakinan seseorang dalam menyelesaikan semua hal yang diperlukan untuk sukses dan memulai wirausaha baru. Secara singkat Campo menyimpulkan entrepreneurial self-efficacy didefinisikan sebagai sejauh mana seseorang percaya untuk mampu berhasil memulai usaha bisnis baru. Jadi, entrepreneurial selfefficacy dalam penelitian ini adalah keyakinan seseorang terhadap kemampuannya untuk mampu melakukan berbagai keterampilan yang diperlukan untuk membuat peluang wirausaha baru.

5. Locus of control

Konsep mengenai locus of control berasal dari teori Julian Rotter atas dasar teori belajar sosial. Rotter menjelaskan bahwa locus of control adalah konsep yang menggambarkan persepsi individu dalam merespon peristiwa yang terjadi di dalam hidup seseorang. Lebih spesifik, locus of control diartikan sebagai seseorang yang mengalokasikan kemampuan merespon yang bersumber dari internal (dalam diri individu) atau eksternal (nasib, keberuntungan, dan kesempatan) (Larsen \& Buss, 2008). Levenson (1981) menjelaskan bahwa locus of control sebagai konstruk pengendalian untuk melihat penguatan yang memengaruhi perilaku seseorang baik yang bersumber pada orang itu sendiri (internal locus of control) atau karena kebetulan, nasib, atau pengaruh orang lain (external locus of control). Jadi, locus of control dalam penelitian ini adalah konstruk pengendalian diri untuk penguatan yang memengaruhi perilaku seseorang baik yang bersumber pada orang itu sendiri (internal locus of control) atau karena kebetulan, nasib, atau pengaruh orang lain (external locus of control).

Levenson (1981) membagi locus of control menjadi dua dimensi, yaitu internal locus of control dan external locus of control.

1. Internal locus of control, merupakan keyakinan akan kendali individu mengenai perilaku dan tindakan yang menjadi penguat berasal dari diri sendiri. 
2. External locus of control. Levenson (1981) membagi external control menjadi dua bagian, yaitu powerful others dan chance. Powerful others, yaitu keyakinan akan kendali individu mengenai perilaku dan tindakan yang menjadi penguatnya berasal dari pengaruh orang lain. Chance, merupakan keyakinan akan kendali individu mengenai perilaku dan tindakannya yang menjadi penguat bersumber karena kebetulan, kesempatan, keberuntungan, dan nasib.

6. Risk taking propensity

Risk taking dapat dikonseptualisasikan sebagai orientasi individu terhadap mengambil risiko dalam situasi pengambilan keputusan (Sexton \& Bowman, 1985 dalam Stewart \& Roth, 2001). Dalam teori klasik, risiko sering dipandang sebagai fungsi dari variasi dalam distribusi untuk mendapatkan hasil yang mungkin didapat dengan pilihan keputusan yang melibatkan antara risiko dan reward yang didapat (March \& Shapira, 1987 dalam Stewart \& Roth, 2001). Brockhaus (1980) dalam Hyrsky \& Tuunanen (1999) menjelaskan risk taking adalah suatu kemungkinan yang dirasakan menerima rewards terkait dengan keberhasilan sesuatu yang terjadi, tetapi sebelumnya akan menerima konsekuensi terkait dengan kegagalan, sebuah pilihan antara menerima reward disertai dengan konsekuensi kegagalan dalam situasi yang dihadapkan. Sedangkan Nicholson, et al., (2005) mendefinisikan risk taking propensity sebagai tingkat kecenderungan yang orang lakukan atau tidak dalam mengambil berbagai jenis risiko.

Sejumlah teori dan studi empiris mengenai risk taking propensity telah diterbitkan. Model yang ditetapkan oleh Sitkin \& Pablo (1992) adalah yang paling banyak digunakan dalam literatur mengenai risk taking propensity (Nicholson, et al., 2005). Menurut Sitkin \& Pablo (1992) dalam Nicholson, et al., (2005) dua kunci dalam mengkaji risk taking adalah risk perception dan risk propensity. Menurut Sitkin \& Pablo (1992) risk taking propensity dikonseptualisasikan sebagai pertemuan kecenderungan disposisional, masukan kognitif dan pengalaman masa lalu.

Sitkin dan Pablo (1992) dalam Nicholson, et al., (2005) mendefinisikan risk taking propensity sebagai kecenderungan seorang pengambil keputusan baik untuk mengambil atau menghindari risiko. Dari definisi ini dapat tersirat bahwa orientasi risiko berada pada domain keputusan (Nicholson, et al., 2005). Jadi, risk taking propensity dalam penelitian ini adalah tingkat kecenderungan untuk mengambil berbagai jenis risiko disertai dengan konsekuensi kegagalan dalam situasi yang dihadapkan. 


\section{Hipotesis Penelitian}

\section{Hipotesis Mayor}

$\mathbf{H}_{1}$ : Terdapat pengaruh yang signifikan need for achievement, need for autonomy, entrepreneurial self-efficacy, internal locus of control, external locus of control, risk taking propensity, dan gender terhadap intensi berwirausaha.

\section{Hipotesis Minor}

$\mathbf{H}_{1}$ : $\quad$ Terdapat pengaruh yang signifikan need for achievement terhadap intensi berwirausaha.

$\mathbf{H}_{2}$ : Terdapat pengaruh yang signifikan need for autonomy terhadap intensi berwirausaha.

$\mathbf{H}_{3}$ : Terdapat pengaruh yang signifikan entrepreneurial self-efficacy terhadap intensi berwirausaha.

$\mathbf{H}_{4}$ : $\quad$ Terdapat pengaruh yang signifikan internal locus of control terhadap intensi berwirausaha.

$\mathbf{H}_{5}$ : Terdapat pengaruh yang signifikan external locus of control terhadap intensi berwirausaha.

$\mathbf{H}_{6}$ : Terdapat pengaruh yang signifikan risk taking propensity terhadap intensi berwirausaha.

$\mathbf{H}_{7}$ : Terdapat pengaruh yang signifikan gender terhadap intensi berwirausaha.

\section{METODE PENELITIAN}

Populasi dalam penelitian ini yaitu siswa SMKN 20 Jakarta yang berjumlah 716 orang. Sampel penelitian ini mencakup siswa SMKN 20 Jakarta baik itu laki-laki maupun perempuan. Siswa yang menjadi populasi dalam penelitian ini memiliki kriteria sebagai berikut:

1. Tercatat aktif sebagai siswa SMKN 20 Jakarta per September 2013

2. Siswa merupakan kelas X, XI, dan XII

3. Siswa telah mengikuti mata pelajaran kewirausahaan di sekolah

Adapun prosedur penetapan sampel yang akan digunakan berjenis probability sampling dengan teknik proportionate stratified random sampling. Disebut probability sampling karena semua subyek dalam populasi memiliki peluang yang sama untuk dipilih sebagai sampel. Digunakan teknik proportionate stratified random sampling karena menggunakan bidang kejuruan sebagai penggolongan dalam pengambilan sampel (Kerlinger \& Lee, 2000). Dalam penelitian ini bidang kejuruan yang dimaksud adalah sebagai berikut:

1. Administrasi perkantoran

2. Akuntansi

3. Pemasaran 


\section{HASIL PENELITIAN}

\section{Analisis regresi variabel penelitian}

Pada tahapan ini hipotesis diuji dengan teknik analisis regresi berganda dan menggunakan software SPSS 16. Dalam regresi ada tiga hal yang dilihat, yaitu pertama melihat besaran $\mathrm{R}$ square untuk mengetahui berapa persen (\%) varians DV yang dijelaskan oleh IV, kedua apakah secara keseluruhan IV berpengaruh secara signifikan terhadap DV, kemudian ketiga melihat signifikan atau tidaknya koefisien regresi dari masing-masing IV. Langkah pertama melihat besaran $\mathrm{R}$ square untuk mengetahui berapa persen (\%) varians DV yang dijelaskan oleh IV. Selanjutnya untuk tabel $R$ square, dapat dilihat pada tabel 1 berikut di bawah ini.

\section{Tabel 1}

\section{Tabel R Square}

\begin{tabular}{ccccc}
\hline & & & & \multicolumn{2}{c}{$\begin{array}{c}\text { Std. Error of the } \\
\text { Model }\end{array}$} & R & R Square Adjusted R Square & Adimate \\
\hline 1 & $.476^{\mathrm{a}}$ & .226 & .202 & 7.91770 \\
\hline
\end{tabular}

Dari tabel 1 dapat kita lihat bahwa perolehan R square sebesar 0.226 atau $22.6 \%$. Artinya proporsi varians dari intensi berwirausaha yang dijelaskan oleh semua variabel independen adalah sebesar $22.6 \%$, sedangkan $77.4 \%$ sisanya dipengaruhi oleh variabel lain di luar penelitian ini.

Langkah kedua menganalisis dampak dari seluruh variabel independen terhadap intensi berwirausaha. Adapun hasil uji $\mathrm{F}$ dapat dilihat pada tabel 2 berikut di bawah ini.

\section{Tabel 2}

Tabel Anova

\begin{tabular}{cccccc}
\hline Model & Sum of Squares & df & Mean Square & F & Sig \\
& & & & & \\
Regression & 4130.277 & 7 & 590.040 & 9.412 & .000 \\
Residual & 14105.241 & 225 & 62.690 & & \\
Total & 18235.519 & 232 & & & \\
\hline
\end{tabular}

Jika melihat kolom signifikansi (kolom ke 6 dari kiri) diketahui bahwa sig $<0.05$, maka hipotesis nihil yang menyatakan tidak ada pengaruh yang signifikan dari seluruh variabel independen terhadap intensi berwirausaha ditolak. Artinya, ada pengaruh yang signifikan dari need for achievement, need for autonomy, entrepreneurial self-efficacy, internal locus of control, external locus of 
control, risk taking propensity, dan juga variabel demografi gender terhadap intensi berwirausaha.

Langkah terakhir adalah melihat koefisien regresi tiap variabel independen. Jika nilai $t>1.96$ maka koefisien regresi tersebut signifikan yang berarti bahwa variabel independen tersebut memiliki dampak yang signifikan terhadap intensi berwirausaha. Adapun penyajiannya ditampilkan pada tabel 3 berikut di bawah ini.

\section{Tabel 3}

\section{Koefisien Regresi}

\begin{tabular}{|c|c|c|c|c|c|}
\hline \multirow{2}{*}{ Model } & \multicolumn{2}{|c|}{$\begin{array}{l}\text { Unstandardized } \\
\text { Coefficients }\end{array}$} & \multirow{2}{*}{$\begin{array}{c}\text { Standardized } \\
\text { Coefficients }\end{array}$} & \multirow{2}{*}{$\mathbf{t}$} & \multirow{2}{*}{ Sig. } \\
\hline & B & $\begin{array}{l}\text { Std. } \\
\text { Error }\end{array}$ & & & \\
\hline (Constant) & 30.809 & 8.372 & & 3.680 & .000 \\
\hline Need for achievement & .135 & .070 & .136 & 1.928 & .055 \\
\hline Need for autonomy & -.184 & .087 & -.141 & -2.123 & .035 \\
\hline Entrepreneurial self-efficacy & .262 & .074 & .255 & 3.522 & .001 \\
\hline Internal locus of control & .141 & .070 & .126 & 2.004 & .046 \\
\hline External locus of control & .022 & .057 & .024 & .396 & .692 \\
\hline Risk taking propensity & .008 & .068 & .008 & .119 & .905 \\
\hline Gender & .050 & 1.356 & -.002 & -.037 & .971 \\
\hline
\end{tabular}

Berdasarkan tabel 3 dapat disampaikan persamaan regresi sebagai berikut di bawah ini (* signifikan).

Intensi berwirausaha $=30.809+0.135$ need for achievement -0.184 need for autonomy* +0.262 entrepreneurial self-efficacy ${ }^{*}+0.141$ internal locus of control $^{*}+0.022$ external locus of control +0.008 risk taking propensity +0.050 gender

Dari tabel 3, untuk melihat signifikan atau tidaknya koefisien regresi yang dihasilkan, dilihat nilai pada kolom signifikansi (kolom paling kanan). Jika sig $<0.05$, maka koefisien regresi yang dihasilkan signifikan pengaruhnya terhadap intensi berwirausaha dan sebaliknya. Dari hasil di atas terdapat tiga koefisien regresi yang signifikan yaitu need for autonomy, entrepreneurial self-efficacy, dan internal locus of control. Variabel lainnya menghasilkan koefisien regresi yang tidak signifikan. Hal ini berarti bahwa dari 7 hipotesis minor hanya terdapat tiga yang signifikan. Penjelasan dari nilai koefisien regresi yang diperoleh masing - masing variabel independen adalah sebagai berikut di bawah ini.

1. Variabel need for achievement memiliki nilai koefisien regresi sebesar 0.135 dengan signifikansi 0.055 (sig > 0.05), yang 
berarti bahwa tidak terdapat pengaruh yang signifikan need for achievement terhadap intensi berwirausaha.

2. Variabel need for autonomy memiliki nilai koefisien regresi sebesar -0.184 dengan signifikansi 0.035 (sig < 0.05), yang berarti bahwa terdapat pengaruh yang signifikan need for autonomy terhadap intensi berwirausaha dengan arah negatif. Artinya semakin tinggi need for autonomy maka semakin rendah intensi berwirausaha.

3. Variabel entrepreneurial self-efficacy memiliki nilai koefisien regresi sebesar 0.262 dengan signifikansi 0.001 (sig < 0.05), yang berarti bahwa terdapat pengaruh yang signifikan entrepreneurial self-efficacy terhadap intensi berwirausaha dengan arah positif. Artinya semakin tinggi entrepreneurial self-efficacy maka semakin tinggi pula intensi berwirausaha.

4. Variabel internal locus of control memiliki nilai koefisien regresi sebesar 0.141 dengan signifikansi 0.046 (sig < 0.05), yang berarti bahwa terdapat pengaruh yang signifikan internal locus of control terhadap intensi berwirausaha dengan arah positif. Artinya semakin tinggi internal locus of control maka semakin tinggi pula intensi berwirausaha.

5. Variabel external locus of control memiliki nilai koefisien regresi sebesar 0.022 dengan signifikansi 0.692 (sig > 0.05), yang berarti bahwa terdapat pengaruh yang tidak signifikan external locus of control terhadap intensi berwirausaha.

6. Variabel risk taking propensity memiliki nilai koefisien regresi sebesar 0.008 dengan signifikansi sebesar 0.905 (sig > 0.05), yang berarti bahwa terdapat pengaruh yang tidak signifikan risk taking propensity terhadap intensi berwirausaha.

7. Variabel gender memiliki nilai koefisien regresi sebesar 0.050 dengan signifikansi sebesar 0.971 (sig $>0.05$ ), yang berarti bahwa terdapat pengaruh yang tidak signifikan gender terhadap intensi berwirausaha. 
Pengujian proporsi varians variabel independen

Tabel 4

Kontribusi Varians Variabel Independen Terhadap Variabel Dependen

\begin{tabular}{|c|c|c|c|c|c|c|c|c|}
\hline \multirow[b]{2}{*}{ Model } & \multirow[b]{2}{*}{$\mathbf{R}$} & \multirow[b]{2}{*}{$\begin{array}{c}\mathbf{R} \\
\text { Square }\end{array}$} & \multirow[b]{2}{*}{$\begin{array}{l}\text { Adjusted } \\
\text { R Square }\end{array}$} & \multirow{2}{*}{$\begin{array}{l}\text { Std. } \\
\text { Error of } \\
\text { the } \\
\text { Estimate }\end{array}$} & \multicolumn{4}{|c|}{ Change Statistics } \\
\hline & & & & & $\begin{array}{c}\text { R } \\
\text { Square } \\
\text { Change }\end{array}$ & $\begin{array}{c}\text { F } \\
\text { Change df }\end{array}$ & f1 df2 2 & $\begin{array}{l}\text { Sig. F } \\
\text { Change }\end{array}$ \\
\hline 1 & $.338^{a}$ & .114 & .110 & 8.36236 & .114 & 29.772 & 1231 & .000 \\
\hline 2 & $.401^{\mathrm{b}}$ & .1 & .154 & & .047 & 12. & 123 & .000 \\
\hline 3 & $.460^{c}$ & .211 & .201 & 7.92 & .051 & 14.694 & 1229 & .000 \\
\hline 4 & $.475^{\mathrm{d}}$ & .22 & .212 & & .014 & 4.246 & 122 & .040 \\
\hline 5 & $.476^{\mathrm{e}}$ & .226 & .209 & 7.8 & .001 & .167 & 1227 & 683 \\
\hline 6 & $.476^{\mathrm{f}}$ & .226 & .206 & 7.90 & .000 & .021 & 1226 & .884 \\
\hline 7 & $.476^{\mathrm{g}}$ & .226 & .202 & 7.91770 & .000 & .001 & 1225 & .971 \\
\hline
\end{tabular}

Dari tabel 4 di atas, dapat dijelaskan sebagai berikut:

1. Variabel need for achievement memberikan sumbangan sebesar $11.4 \%$ terhadap varians intensi berwirausaha. Sumbangan tersebut signifikan dengan $\mathrm{F}=29.772$, df1 $=1$, dan df2 $=231$

2. Variabel need for autonomy memberikan sumbangan sebesar $4.7 \%$ terhadap varians intensi berwirausaha. Sumbangan tersebut signifikan dengan $\mathrm{F}=12.790$ dan $\mathrm{df}=230$

3. Variabel entrepreneurial self-efficacy memberikan sumbangan sebesar $5.1 \%$ terhadap varians intensi berwirausaha. Sumbangan tersebut signifikan dengan $\mathrm{F}=14.694$, df1 $=1$, dan df2 $=229$

4. Variabel internal locus of control memberikan sumbangan sebesar $1.4 \%$ terhadap varians intensi berwirausaha. Sumbangan tersebut signifikan dengan $\mathrm{F}=4.246$, $\mathrm{df} 1=1$, dan $\mathrm{df} 2=228$

5. Variabel external locus of control memberikan sumbangan sebesar $0.1 \%$ terhadap varians intensi berwirausaha. Sumbangan tersebut tidak signifikan dengan $\mathrm{F}=0.167, \mathrm{df} 1=1$, dan $\mathrm{df} 2=$ 227

6. Variabel risk taking propensity memberikan sumbangan sebesar $0.0 \%$ terhadap varians intensi berwirausaha. Sumbangan tersebut tidak signifikan dengan $\mathrm{F}=0.021$, df1 $=1$, dan df $2=$ 226

7. Variabel gender memberikan sumbangan sebesar $0.0 \%$ terhadap varians intensi berwirausaha. Sumbangan tersebut tidak signifikan dengan $F=0.001, \mathrm{df} 1=1$, dan $\mathrm{df} 2=225$ 
Demikian dapat disimpulkan bahwa ada 4 variabel independen yang signifikan sumbangannya terhadap intensi berwirausaha, yaitu need for achievement, need for autonomy, entrepreneurial self-efficacy, dan internal locus of control. Jika dilihat dari besarnya pertambahan $\mathrm{R}^{2}$ yang dihasilkan setiap kali dilakukan penambahan variabel independen (sumbangan proporsi varian yang diberikan). Dari empat variabel independen tersebut dapat dilihat variabel yang paling besar memberikan sumbangan terhadap intensi berwirausaha. Hal tersebut dapat diketahui dengan melihat $\mathrm{R}^{2}$ change, semakin besar maka semakin banyak sumbangan yang diberikan terhadap variabel dependen. Dari tabel 1.6 di atas dapat diketahui bahwa variabel independen yang secara signifikan memberikan sumbangan dari yang terkecil sampai terbesar yaitu internal locus of control dengan $\mathrm{R}^{2}$ change sebesar 0.014 atau $1.4 \%$, need for autonomy dengan $\mathrm{R}^{2}$ change sebesar 0.047 atau $4.7 \%$, entrepreneurial self-efficacy dengan $\mathrm{R}^{2}$ change sebesar 0.051 atau $5.1 \%$, dan yang terbesar need for achievement dengan $\mathrm{R}^{2}$ change sebesar 0.114 atau $11.4 \%$.

\section{KESIMPULAN DAN SARAN}

\section{Diskusi}

Penelitian ini merupakan salah satu gambaran permasalahan pengangguran di Indonesia, sesuai dengan hasil penelitian tentang tingkat pengangguran terbuka (TPT) menurut pendidikan tertinggi yang ditamatkan pada tahun 2008 dan 2009 tertinggi yaitu Sekolah Menengah Kejuruan (Sakernas, BPS dalam RPJP Kemenakertrans 2010-2025 Bidang Ketenagakerjaan dan Ketransmigrasian). Dalam data yang didapatkan pada bulan Agustus 2012 terulang kembali SMK berada pada tingkat yang paling tinggi yaitu 9,87\% (Berita Resmi Statistik, 2012 diunduh dari bps.go.id). Hal tersebut merupakan masalah besar, karena disisi lain SMK merupakan instansi pendidikan yang berorientasi pada pembentukan kreativitas dan kewirausahaan sehingga diharapkan lulusannya juga dapat siap bekerja dan siap membuka usaha (Garis-Garis Besar Program Pembinaan SMK, 2012). Jadi diharapkan penelitian ini dapat membantu dalam pengembangan pendidikan khususnya pada SMK di Indonesia.

Penelitian ini dilakukan di SMK Negeri 20 Jakarta, dengan siswanya sebagai subyek penelitian. Padatnya jam masuk pelajaran di sekolah membuat kesulitan dalam mengatur penyebaran kuesioner. Sistem belajar moving class memungkinkan tersebarnya bidang kejuruan yang diinginkan tersebar diberbagai kelas juga cukup menyulitkan dalam penyebaran kuesioner. Responden yang diperoleh berjumlah 233 orang, diharapkan jumlah tersebut dapat mewakili dari populasi penelitian.

Salah satu variabel yang diteliti dalam penelitian ini yaitu need for achievement. Dari hasil penelitian tidak terdapat pengaruh yang signifikan 
need for achievement terhadap intensi berwirausaha. Hal ini tidak mendukung penelitian sebelumnya yang dilakukan oleh Dehkordi., et al (2012). Penelitian yang dilakukan Dehkordi., et al (2012) menyebutkan bahwa need for achievement merupakan faktor yang paling berpengaruh terhadap intensi berwirausaha. Tentunya pernyataan Dehkordi., et al (2012) sangat bertolak belakang dari hasil penelitian ini. Serupa dalam penelitian yang telah dilakukan oleh Dehkordi., et al (2012), Opoku-Antwi., et al (2012) dalam penelitiannya menjelaskan bahwa need for achievement berpengaruh terhadap intensi berwirausaha. Siswa yang memiliki need for achievement tinggi berarti memiliki kebutuhan yang lebih untuk optimis, memikirkan masa depan, dan mandiri dalam mengerjakan tugas. Kebutuhan yang dihasilkan tersebut berpengaruh terhadap peningkatan intensi berwirausaha pada siswa. Namun dalam penelitian lain, hasil penelitian ini mendukung pada penelitian yang telah dilakukan Indira \& Soenhadji (2010). Hasil dari penelitian Indira \& Soenhadji (2010) yaitu tidak terdapat pengaruh yang signifikan need for achievement terhadap intensi berwirausaha.

Variabel selanjutnya yaitu need for autonomy. Hasil penelitian membuktikan secara signifikan terdapat pengaruh need for autonomy terhadap intensi berwirausaha. Hasil penelitian tersebut mendukung penelitian sebelumnya yang dilakukan oleh Hmieleski \& Corbett (2006). Dalam penelitiannya Hmieleski \& Corbett (2006) menyatakan bahwa ada pengaruh signifikan need for autonomy terhadap intensi berwirausaha. Namun dalam penelitian ini need for autonomy memiliki muatan negatif, yang artinya bahwa apabila seseorang memiliki need for autonomy yang rendah maka semakin tinggi intensi berwirausaha orang tersebut. Murray (1938) menjelaskan need for autonomy sebagai seseorang yang membebaskan diri dari aturan yang mengekang, melawan paksaan dan hambatan, menghindari kekuasaan orang lain, bertindak bebas sesuai dengan keinginan sendiri, dan tidak memiliki keterikatan (Larsen \& Buss, 2002). Dari definisi tersebut dapat disimpulkan bahwa seseorang yang memiliki intensi berwirausaha tinggi dapat digambarkan sebagai seseoarang yang mampu menaati peraturan, menghadapi hambatan, menghadapi kekuasaan orang lain, mengontrol tindakan yang dilakukan, dan bersedia terikat dalam suatu hubungan.

Variabel selanjutnya entrepreneurial self-efficacy. Hasil penelitian membuktikan secara signifikan terdapat pengaruh entrepreneurial self-efficacy terhadap intensi berwirausaha. Hasil penelitian tersebut mendukung penelitian sebelumnya yang dilakukan oleh Izquierdo \& Buelens (2008); Hashemi, Hosseini, \& Rezvanfar (2012); dan Mobaraki \& Zare (2012). Izquierdo \& Buelens (2008) menyatakan bahwa seseorang yang memiliki entrepreneurial self-efficacy yang tinggi maka akan diikuti pula dengan niat berwirausaha yang tinggi pula. Hosseini, \& Rezvanfar (2012) manyatakan bahwa psikologis seseorang merupakan salah satu hambatan dalam memulai berwirausaha, sehingga dalam penelitiannya mengenai 
entrepreneurial self-efficacy diharapkan dapat mengurangi hambatan tersebut, yaitu dengan tingginya entrepreneurial self-efficacy seseorang maka akan tinggi pula intensi berwirausahanya. Mobaraki \& Zare (2012) dalam penelitiannya menyebutkan bahwa nanti dalam penelitian masa depan akan ada cara bagaimana entrepreneurial self-efficacy dapat masuk ke dalam pelajaran di sekolah, serta mampu menciptakan dan meningkatkan keyakinan seseorang dalam berwirausaha.

Variabel selanjutnya internal locus of control \& external locus of control. Internal locus of control secara signifikan berpengaruh terhadap intensi berwirausaha. Sedangkan external locus of control secara signifikan tidak berpengaruh terhadap intensi berwirausaha. Hasil penelitian tersebut mendukung penelitian sebelumnya yang dilakukan oleh Opoku-Antwi., et al (2012). Dalam penelitiannya Opoku-Antwi., et al (2012) menyebutkan bahwa seseorang dengan internal locus of control lebih berpengaruh terhadap intensi berwirausaha dibandingkan dengan external locus of control. Seseorang yang memiliki internal locus of control yang tinggi, maka diikuti pula dengan intensi berwirausaha yang tinggi pula.

Variabel selanjutnya risk taking propensity secara signifikan tidak berpengaruh terhadap intensi berwirausaha. Hasil penelitian tersebut tidak mendukung penelitian sebelumnya yang dilakukan oleh Hassan \& Wafa (2005). Dalam penelitiannya, Hassan \& Wafa (2005) menyatakan bahwa risk taking propensity berpengaruh secara signifikan terhadap intensi berwirausaha walaupun dengan proporsi varians yang sangat kecil. Dalam penelitian ini justru malah sebaliknya, risk taking propensity tidak memiliki pengaruh secara signifikan terhadap intensi berwirausaha. Siswa SMK yang merupakan sampel dalam penelitian ini, mereka belajar mengenai kewirausahaan sejak awal masuk sekolah. Hal tersebut dapat menjadi kemungkinan dalam pola pikir siswa yang tidak lagi memikirkan bahwa berwirausaha itu merupakan sebuah pilihan yang beresiko, melainkan sebuah pilihan yang baik. Selain teori yang dipaparkan oleh guru dalam pelajaran, siswa juga mendapatkan pengalaman praktek berwirausaha di sekolah, sehingga wirausaha bukan hal asing lagi dalam pemikiran mereka.

Variabel selanjutnya gender secara signifikan tidak berpengaruh terhadap intensi berwirausaha. Hasil penelitian tersebut tidak mendukung penelitian sebelumnya yang dilakukan oleh Hassan \& Wafa (2005). Dalam hasil penelitiannya menyebutkan gender memiliki pengaruh yang signifikan terhadap intensi berwirausaha. Hasil yang sama juga ditemukan dalam penelitian Nishantha (2009). Dalam penelitiannya menyebutkan bahwa laki-laki lebih memiliki pengaruh yang besar dibandingkan dengan perempuan. 


\section{Saran}

Untuk penelitian selanjutnya, peneliti menyarankan sebagai berikut:

\section{Saran Teoritis}

1. Mempertimbangkan hasil penelitian ini yang menemukan bahwa besar sumbangan variabel independen terhadap intensi berwirausaha hanya sebesar $22.6 \%$, dan sisanya $77.4 \%$ dari variabel lain. Peneliti lain yang tertarik meneliti variabel dependen yang sama agar melibatkan variabel independen lain yang memengaruhi tingkat intensi berwirausaha selain variabel independen dalam penelitian ini. Dengan mempertimbangkan variabel tersebut, diharapkan penelitian selanjutnya akan lebih menyempurnakan hasil dalam penelitian ini.

2. Beberapa instrumen dalam penelitian ini menggunakan alat ukur baku dari bahasa asing yang memiliki istilah yang jarang digunakan. Responden dalam penelitian ini mempertanyakan istilah yang digunakan tersebut, sehingga disarankan agar penelitian selanjutnya lebih memahami karakteristik sampel yang digunakan dan dikaitkan dalam pembuatan instrumen penelitian agar mudah dipahami responden.

3. Dari segi instrumen penelitian yang digunakan, disarankan lebih berhati-hati dalam menggunakan alat ukur yang dikembangkan sendiri oleh peneliti. Lebih memperhatikan dalam menerapkan kaidah pembuatan item pengukuran, sehingga dapat meningkatkan hasil uji validitas dalam instrumen penelitian yang digunakan. Mengingat banyak yang tidak valid dari hasil uji validitas instrumen yang dikembangkan sendiri oleh peneliti.

4. Ditemukan dalam penelitian ini perbedaan antara masalah yang didapatkan dari jurnal internasional dengan masalah yang ada di Indonesia, seperti tidak signifikannya beberapa variabel independen yang digunakan dalam penelitian ini. Peneliti selanjutnya disarankan sebelum mengambil data kepada sampel penelitian, lebih baik melakukan try out terlebih dahulu. Hal tersebut sangat bermanfaat untuk mengoreksi item penelitian agar lebih sempurna ketika digunakan untuk mengambil sampel yang sebenarnya.

\section{Saran Praktis}

1. Berdasarkan kesimpulan dari hasil penelitian ini maka hasil tersebut diharapkan dapat digunakan sebagai masukan yang bermanfaat untuk instansi pendidikan, khususnya SMKN 20 Jakarta maupun lembaga/departemen yang menaunginya. Terutama dalam hal pengendalian operasional kurikulum yang 
telah dikembangkan agar sesuai dengan tujuan pembelajaran dimaksud.

2. Hasil penelitian ini diharapkan dapat membantu mengembangkan kurikulum pembelajaran terkait kewirausahaan di instansi pendidikan khususnya SMKN 20 Jakarta secara tertulis dan prakteknya di lapangan dengan memerhatikan variabel psikologis yang memiliki pengaruh dalam penelitian ini, yaitu need for autonomy, entrepreneurial selfefficacy, dan internal locus of control.

3. Bagi orang tua siswa diharapkan untuk lebih mendukung anaknya agar lebih yakin dalam beraktivitas. Dalam penelitian ini faktor keyakinan memiliki peran dalam memengaruhi intensi berwirausaha siswa, yaitu entrepreneurial self-efficacy.

4. Berdasarkan hasil penelitian ini ditemukan bahwa intensi berwirausaha pada siswa SMKN 20 Jakarta tergolong rendah, dari 233 siswa yang menjadi sampel penelitian terdapat 119 siswa atau $51,1 \%$ dari keseluruhan sampel termasuk dalam kategori rendah. Diharapkan hasil tersebut dapat dijadikan bahan untuk memperketat seleksi dan penerimaan siswa agar yang masuk menjadi siswa SMK merupakan benar ingin berwirausaha, tidak sekedar hanya ingin melanjutkan sekolah. Kemudian dari tenaga pendidik juga dapat ditingkatkan kualitasnya dengan menyeleksi guru yang memiliki keterampilan berwirausaha serta didukung untuk dapat mengikuti berbagai pelatihan terkait tentang kewirausahaan.

\section{DAFTAR PUSTAKA}

Afzalurrahman. (1997). Muhammad Sebagai Seorang Pedagang. Jakarta: Penerbit Yayasan Swarna Bhumy

Ajzen, I. (2005). Attitudes, Personality, and Behavior. Maidenlead. UK: Open University Press

Ajzen, I. (1991). The Theory of Planned Behavior Organizational Behavior and Human Decision Prosesses. USA: Academic Press, Inc

Alhaj, B., Yusof, M., \& Edama, N. (2011). Entrepreneurial Intention: An Empirical Study of Community College Students in Malaysia. Jurnal Personalia Pelajar, Bil $14: 45-58$. Malaysia

Ariani, D.W. (2006). Need for Achievement dalam Kinerja Individu: Tinjauan Konseptual. Fakultas Ekonomi Universitas Atma Jaya Yogyakarta

Badan Pusat Statistik. (2012). Keadaan Ketenagakerjaan Agustus 2012. Berita Resmi Statistik No. 75/11/Th. XV 
Brown, Eleanor. R. (2010). Generation $X$ and $Y: A$ comparative analysis of entrepreneurial intent. Gordon Institute of Business Science, University of Pretoria.

Campo, José L.M. (2011). Analysis of the influence of self-efficacy on entrepreneurial intentions. Prospect. Vol. 9, No. 2

Castillo, M. R. (2009). Autonomy as a Foundation of Human Development: A Conceptual Model to Study Individual Autonomy. Maastricht Graduate School of Governance. MGSoG/2009/WP011. Maastricht University

Chaplin, C.P. 2006. Kamus Lengkap Psikologi. Penerjemah: Kartini Kartono. Jakarta: Rajawali Pers

Dehkordi, A., Sasani, A., Fathi, M., dan Khanmohammadi, E. (2012). Investigating the Effect of Emotional Intelligence and Personality Traits on Entrepreneurial Intention Using the Fuzzy DEMATEL Method. International Journal of Business and Social Science Vol. 3 No. 13; July 2012. USA: Centre for Promoting Ideas

De Noble, A.F., Jung, Dong., Ehrlich, S.B. (1999). Entrepreneurial SelfEfficacy: The Development of a Measure and Its Relationship to Entrepreneurial Action. San Diego State University

Direktorat Pembinaan Sekolah Menengah Kejuruan. (2012). Garis-Garis Besar Program Pembinaan SMK Tahun 2012. Direktorat Jenderal Pendidikan Menengah, Kementerian Pendidikan dan Kebudayaan

Fatoki, Olawale. (2010). Graduate Entrepreneurial Intention in South Africa: Motivations and Obstacles. International Journal of Business and Management. South Africa: Department of Business Management, University of Fort Hare

Feist, \& Feist. (2010). Teori Kepribadian Jil. 2. Jakarta: Salemba Humanika

Fishbein, M., \& Ajzen, I. (1975). Bilief, Attitude, Intention, and Behavior. An Introduction to Theory and Research. Reading, MA: Addison Wesley

Friedman, H., \& Schustack, M. (2009). Personality: Classic Theories and Modern Research 4th Edition. Boston: Pearson Higher Education

Gelard, P., \& Saleh, K.E. (2010). Impact of some contextual factors on entrepreneurial intention of university students. African Journal of Business Management Vol. 5(26), pp. 10707-10717, 28 October, 2011

Guifang, Z., Peng, C., Luqing, F., \& Ziqi, C. An Emprical of College CarveOut Education on Entrepreneurial Intention. China: School of Economics and Management, Beijing Forestry University

Gubruz, G., \& Aykol, S. (2008). Entrepreneurial Intention of Young Educated Public in Turkey. Turkey: Marmara University

Hassan, R.A \& Wafa, S.A. (2005). Predictors Towards Entrepreneurial Intention: A Malaysian Case Study. Asian Journal of Business and Management Sciences Vol. 01 No. 11. [01-05] 
Hashemi, S., Hosseini, S., \& Rezvanfar, A. (2012). Explaining Entrepreneurial Intention among Agricultural Students: Effects of Entrepreneurial Self Efficacy and College Entrepreneurial Orientation. Journal of Business Management

Hmieleski, K.M and Corbett, A.C (2006). Proclivity for Improvisation as a Predictor of Entrepreneurial Intentions. Journal of Small Business Management 2006 44(1), pp. 45-63

Hmieleski, K.M., \& Baron, R.A. (2008). When does entrepreneurial self-efficacy Enhance versus reduce firm performance. Strategic Entrepreneurship J., 2: 57-72

Hyrsky, Kimmo., \& Tuunanen, Mika. (1999). Innovativeness and Risk-taking Propensity: A Cross-Cultural Study of Finnish and U.S. Entrepreneurs and Small Business Owners. University of Jyväskylä, School of Business \& Economics

Indira, C., Soenhadji, I., (2010). Students Entrepreneurship Intention: Study of Comparison Between Java and Non Java. Jurusan Manajemen, Fakultas Ekonomi. Depok: Universitas Gunadarma

Indarti, N. dan Rostiani, R. (2008). Intensi Kewirausahaan Mahasiswa: Studi Perbandingan Antara Indonesia, Jepang dan Norwegia. Jurnal Ekonomika dan Bisnis Indonesia, Vol. 23, No. 4, Oktober 2008

Izquierdo, E., Buelens, M. (2008). Competing Models of Entrepreneurial SelfEfficacy and Attitudes. Internationalizing Entrepreneurship Education and Training Conference. USA: Oxford

Kementerian Tenaga Kerja dan Transmigrasi (2012). Rencana Pembangunan Jangka Panjang 2010-2025 Bidang Ketenagakerjaan dan Ketransmigrasian. Peraturan Menteri Tenaga Kerja dan Transmigrasi Republik Indonesia

KEP. 16/MEN/II/2010. (2010). Perluasan Kesempatan Kerja dan Peningkatan Kesejahteraan Tenaga Kerja Melalui Penciptaan dan Pengembangan Wirausaha. Kesepakatan Bersama antara Kementerian Tenaga Kerja dan Transmigrasi, Kementerian Koperasi dan Usaha Kecil dan Menengah, Kementerian Perindustrian dengan Kementerian Kelautan dan Perikanan, dan Kementerian Pemuda dan Olah Raga

Kerlinger, Fred N. (2002). Foundations of Behavioral Research. 3rd ed. New York: Holt, Rinehart and Winston Publishing Co

Khodabakhshi, S., \& Talebi, K. (2012). Evaluating the Role of Entrepreneurial Self-Efficacy on Entrepreneurial Intention of Tehran University (Case Study of Engineering Campus). Journal of Education and Vocational Research Vol. 3, No. 3, pp. 82-88. Iran: Faculty of Entrepreneurship, University of Tehran

Larsen, Randy J., \& David, M. Buss. (2002). Personality psychology: Domains of knowladge about human nature (1st ed). New York. McGraw Hill 
Levenson, Hanna. (1981). Differentiating Among Internality, Powerful Others, and Chance. Research with The Locus of Control Construct (Vol. 1). Academic Press

Linan, F., \& Chen, Y. (2006). Testing the Entrepreneurial Intention Model On a Two-Country Sample. Spain: Departament d'Economia de l'Empresa, Facultat de Ciències Econòmiques i Empresarials

Mahshunah, Shofia. (2010). Hubungan Antara Self Efficacy Dengan Intensi Berwirausaha (Penelitian Pada Siswa Kelas XII SMK Ibu Kartini Semarang). Under Graduates thesis, Universitas Negeri Semarang

Mobaraki, M.H., Zare, Y.B. (2012). Designing Pattern of Entrepreneurial SelfEfficacy on Entrepreneurial Intention. Information Management and Business Review Vol. 4, No. 8, pp. 428-433

Muzayini, Ayi. E. K. (2008). Indahnya Berbisnis Dengan Tuhan. Tangerang: Penerbit Fatihah Publishing

Nicholson., et al. (2005). Risk Propensity and Personality. London: Economic and Social Research Council

Nishantha, Busige (2009). Influence of Personality Traits and Socio-demographic Background of Undergraduate Students on Motivation for Entrepreneurial Career: The Case. of Sri Lanka. Euro-Asia Management Studies Association (EAMSA) Conference. Japan: Doshisha Business School

Nwankwo, B., Marire, M., Kanu, G., Balogun, S., \& Uhiara, A. (2012). Gender-Role Orientation and Self Efficacy as Correlates of Entrepreneurial Intention. European Journal of Business and Social Sciences, Vol. 1, No. 6. Nigeria

Ogundipe, S., Kosile, B., Olaleye, V., Ogundipe, L. (2012). Entrepreneurial Intention among Business and Counseling Students in Lagos State University Sandwich Programme. Journal of Education and Practice Vol 3, No 14

Opoku-Antwi, G., Amofah, K., Koffuor, K., \& Yakubu, A. (2012). Entrepreneurial Intention Among Senior High School Students in the Sunyani Municipality. International Review of Management and Marketing Vol. 2, No. 4, 2012, pp.210-219

Pedhazur, E.J, (1997), Multiple Regression in Behavioral Research (3th Ed). CBS College Publishing, New York

Prihatsanti, Unika. (2010). Hubungan Kepuasan Kerja Dan Need For Achievement Dengan Kecenderungan Resistance To Change Pada Dosen Undip Semarang. Semarang: Fakultas Psikologi Universitas Diponegoro

Santrock, J.W. (2009). Psikologi Pendidikan Edisi 3 Buku 2. Jakarta: Salemba Humanika

Sieger, P., Fueglistaller, U., \& Zellweger, T. (2011). Entrepreneurial Intentions and Activities of Students across the World. International report of the Global University Entrepreneurial Spirit Students' Survey project (GUESSS 2011). St.Gallen: Swiss Research Institute of Small 
Business and Entrepreneurship at the University of St.Gallen (KMUHSG)

Stewart, W.H., \& Roth, P.L. (2001) Risk Propensity Differences Between Entrepreneurs and Managers: A Meta-Analytic Review.Arthur M. Spiro Center for Entrepreneurial Leadership Working PaperNumber: 99101

Suryana, (2009). Kewirausahaan: Pedoman praktis kita dan proses menuju sukses. Jakarta: Salemba empat

Thompson, Edmund. (2009). Individual Entrepreneurial Intent: Construct Clarification and Development of an Internationally Reliable Metric. Entrepreneurship Theory and Practice. Baylor University

Turker, D., Selcuk, S. (2008). Which factors affect entrepreneurial intention of university students? Journal of European Industrial Training Vol. 33 No.

2. Turkey: Emerald Group Publishing Limited

Umar, Jahja (2010). Personality Needs, Kepuasan, \& Prestasi Kerja.UIN Jakarta Press: Ciputat

UU No. 69 Tahun 2009. Percepatan Pelayanan Perizinan dan Non Perizinan Untuk Memulai Usaha. Peraturan Bersama Menteri Dalam Negeri, Menteri Hukum dan Hak Asasi Manusia, Menteri Perdagangan, Menteri Tenaga Kerja dan Transmigrasi, dan Kepada Badan Koordinasi Penanaman Modal

Winardi, J. (2004). Entrepreneur \& Entrepreneurship. Jakarta: Prenada Media

Woolfolk, Anita.(2009). Educational Psychology Active Learning Edition. Yogyakarta: Pustaka Pelajar

Zain, Zahariah.M. (2010). Entrepreneurship Intention Among Malaysian Business Students. Canadian Social Science Vol. 6, No. 3, 2010, pp. 3444

\section{Situs internet:}

http://bps.go.id diunduh pada tanggal 15 November 2012 pukul 21.00 WIB http://www.depkop.go.id diunduh pada tanggal 20 November 2012 pukul $20.00 \mathrm{WIB}$

http://www.depnakertrans.go.id/perundangan.html,1,343,10 diunduh pada tanggal 27 Desember 2012 pukul 10.10 WIB

http://www.depnakertrans.go.id/uploads/doc/RPJP.pdf diunduh pada tanggal 27 Desember 2012 pukul 11.40 WIB

http://www.ditpsmk.net/ diunduh pada tanggal 28 Desember 2012 pukul 22.10 WIB 
